\title{
Quantitative enzyme immunoassay and semiquantitative immunohistochemistry of oestrogen and progesterone receptors in endometriotic tissue and endometrium
}

\author{
Agneta Bergqvist, Mårten Fernö, Lambert Skoog
}

\begin{abstract}
Background-The capacity of different tissues to respond to steroids has been evaluated mainly according to the concentrations of oestrogen (ER) and progesterone (PR) receptors, which may be assayed either in tissue homogenates or histochemically. These two principles have been used in different studies of endometriotic tissue, giving somewhat different results, probably because the tissue is heterogeneously mixed with fibrotic tissue and blood cells to various degrees.

Aims-To compare a quantitative and a qualitative, semiquantitative immunocytochemical assay for ER and $P R$ in a heterogenous tissue (endometriotic) and a similar but more homogenous tissue (endometrium).

Methods-ER and PR concentrations were measured using enzyme immunoassay (EIA) and immunocytochemistry (ICA) in the same tissue samples (endometriotic tissue from 31 women and endometrium from 19 of the same women).

Results-There was a significant correlation between PR concentration (using EIA) and semiquantitation of $P R$ using PRICA in endometrial epithelium $(p=0.028)$. The correlation between the two techniques for ER concentration was not significant. In endometriotic tissue no correlation was found between the two techniques for ER or PR.

Conclusions-These data show that in heterogeneous tissues like endometriotic tissue different techniques for measuring steroid receptors may produce substantially different results. The two techniques (EIA and ICA) are complementary and a combination of the two techniques might aid in determining optimal treatment. (f Clin Pathol 1997;50:496-500)
\end{abstract}

Keywords: oestrogen receptors; progesterone receptors; endometriosis; enzyme immunoassay; immunocytochemistry

Assays of steroid receptors have gained interest resulting in better guidelines for treating various diseases. Steroid receptors can be assayed either quantitatively in tissue homogenates or qualitatively by localising receptors to the tissue structures, a method that also gives semiquantitative data on the number of recep- tors. A quantitative steroid receptor assay in tissue homogenates gives no information about the distribution of oestrogen (ER) and progesterone (PR) receptors, and the inclusion of a large quantity of non-endometriotic cells in the homogenate results in a dilution of the total steroid receptor content. In contrast, an immunocytochemical technique localises the steroid receptors but only a few histological sections may be evaluated that may not be representative. In breast cancer tissue a good correlation between the quantitative enzyme immunoassay and the semiquantitative immunocytochemical technique has been shown. ${ }^{1-6}$ However, in more heterogeneous tissues the correlation might be less pronounced, and results from only one type of assay might be less representative and insufficient. Quantitative assays of ER and PR in endometriotic tissue compared with endometrium obtained simultaneously from the same woman have shown that the concentrations in endometriotic tissue are significantly lower than in the endometrium. ${ }^{78}$ This difference is most pronounced in the proliferative phase of the menstrual cycle. ${ }^{9}$ Immunocytochemical localisation of ER and PR in eutopic and ectopic endometrium has also shown a varying staining pattern in the glandular and stromal cells in different phases of the menstrual cycle. ${ }^{10-12}$

Endometriotic lesions often consist of glands and cytogenic stroma, interspaced by dense fibrotic ingrowing tissue and diffuse bleedings, which might influence the expression of steroid receptors, as might different growth factors in the surroundings and their interaction with hormonal regulation of cells (fig 1). The changes in receptor expression related to the menstrual cycle vary in endometriotic tissue in different locations. ${ }^{13}$ Ectopic endometrium often presents a heterogeneous histological cycle phase pattern and sometimes no phase pattern, indicating a deficient response to hormonal influence or a defect in steroid receptors compared with normal endometrium. ${ }^{14}{ }^{15} \mathrm{~A}$ comparison between eutopic and ectopic endometrium from the same woman would be a suitable model for a comparison between quantitative and qualitative steroid receptor assays.

The aim of this study was to compare an immunocytochemical localisation of ER 


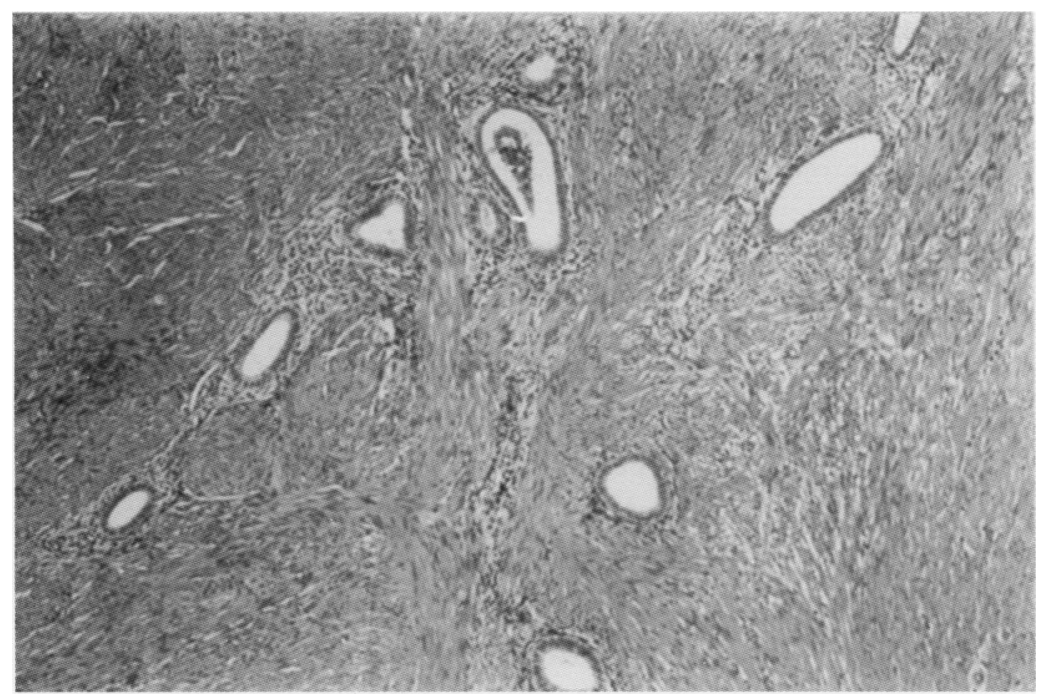

Figure 1 Endometriotic tissue interspaced by other tissue structures such as connective tissue.

(ERICA) and PR (PRICA) and measurement of the receptors using an enzyme immunoassay (EIA) in the same sample of endometrium and endometriotic tissue obtained simultaneously from the same woman.

\section{Methods}

Endometriotic tissue samples, large enough to provide tissue for both assays, were obtained from 31 women at laparotomy. Endometrium was obtained simultaneously by curettage from 19 of the women. One woman was treated with danazol and two were on oral contraceptives at the time of surgery. These patients were excluded from statistical calculations. None of the other women had been on hormonal treatment, had been pregnant or lactating for at least three months before tissue sampling. A total of 34 samples of endometriotic tissue and one sample of adenomyosis were available for both assays (in three patients endometriotic samples were obtained from more than one lesion). Fifteen of the samples were obtained from endometriomas, seven from minor ovarian lesions, five from peritoneal lesions, one from the uterosacral ligament, three from the vagina, two from the bowel, and one from an inguinal lesion.

To obtain as pure an endometriotic tissue sample as possible in the operating room, samples were immediately rinsed in cold physiological saline $\left(4^{\circ} \mathrm{C}\right)$ to remove any blood. The endometriotic tissue covering the inside of the endometriomas was scraped off with the back edge of a knife. Small endometriotic lesions were detached from inappropriate surrounding tissue as far as possible. One part of the tissue sample was fixed in $4 \%$ formalin for histological evaluation and verification after staining with haematoxylin and eosin. A second part was mounted fresh on a piece of cork using Tissue-tek (Miles Inc, Diagnostics Division, Indiana, USA). A further piece of the sample was placed in a small test tube. The two unfixed samples were frozen in liquid nitrogen $\left(-196^{\circ} \mathrm{C}\right)$ and transferred to a $-70^{\circ} \mathrm{C}$ freezer within 30 minutes. The assays were all performed within six months.
ENZYME IMMUNOASSAY

For the quantitative EIA samples were homogenised and ER and PR were analysed both in the cytosol and the nuclear fraction of the homogenate. ${ }^{16}$ Commercial kits with specific monoclonal antibodies towards the steroid receptors were used (Abbott Laboratories, Diagnostics Division, Illinois, USA). The antibodies used were D547 on the bead and $\mathrm{H} 222$ in the conjugate for ER, and KD68 on the bead and B39 in the conjugate for PR. The detection limit was $1 \mathrm{fmol} / \mathrm{ml}$ (according to the manufacturer's instructions). Receptor concentrations were expressed per milligram of DNA. The DNA concentration, determined according to Burton, ${ }^{17}$ was measured in duplicate and only a difference in the replicates of less than $10 \%$ was accepted.

\section{IMMUNOCYTOCHEMICAL ASSAY}

Immunocytochemical assay kits, ERICA and PRICA, both indirect immunoperoxidase techniques, were purchased from Abbott Scandinavia $A B$, (Stockholm, Sweden) and the incubations performed as described previously. ${ }^{13}$ For the immunocytochemical studies three $5 \mu \mathrm{m}$ cryostat sections were cut, one for ER localisation, one for PR localisation, and one stained with haematoxylin and eosin for histological examination. The staining was evaluated separately in epithelial and stroma cells. The frequency of positive cells per 100 scrutinised cells was classified in to five different groups $(0 \%, 25 \%, 50 \%, 75 \%$, or $100 \%$ of the cells positive). The staining intensity was classified in to four different groups (none, weak, moderate, or strong staining). A specific staining index, expressed as TISS (total immune staining score) was used, ${ }^{13}$ calculated from the staining intensity times the fraction of positive cells, giving a maximal score of 20 points. The staining was graded independently by two blinded investigators. The interobserver agreement on staining index was $85 \%$; slides with incongruent gradings were scrutinised again and the results weighted together.

MENSTRUAL CYCLE PHASE

The menstrual cycle phase was calculated according to menstrual cycle day, histological cycle phase in endometrium according to Noyes et $a l,{ }^{18}$ and serum concentration of oestradiol and progesterone in peripheral blood sampled during surgery.

STATISTICAL ANALYSIS

For statistical comparisons Wilcoxon's test was used, and Spearman's rank correlation test was used for correlation calculations; $p<0.05$ was considered significant.

\section{Results}

The mean (SD) age of the women was 37 (5) years. Thirteen of the women were in follicular phase, 14 in luteal phase, and four in menstrual phase. Histological examination of all tissue samples verified that there was an acceptable amount of both glandular epithelium and stroma. The quantitative ER and PR concen- 
Table 1 Quantitative and semiquantitative measurements of oestrogen (ER) and progesterone (PR) receptors in the same endometrial and endometriotic tissue samples obtained simultaneously from the same woman

\begin{tabular}{|c|c|c|c|}
\hline & $\begin{array}{l}\text { Endometrium } \\
\text { mean }(S D)\end{array}$ & $\begin{array}{l}\text { Endometriosis } \\
\text { mean }(S D)\end{array}$ & $p$ value * \\
\hline \multicolumn{4}{|l|}{ Quantitative assay } \\
\hline ERc (fmol/mg DNA) & $2100(1400)$ & $580(710)$ & 0.0002 \\
\hline ERn (fmol/mg DNA) & $430(380)$ & $190(290)$ & 0.0074 \\
\hline PRc (fmol/mg DNA) & $6100(4100)$ & $3300(3900)$ & 0.0012 \\
\hline PRn (fmol/mg DNA) & $640(560)$ & $380(440)$ & 0.0156 \\
\hline \multicolumn{4}{|l|}{ Semiquantitative assay } \\
\hline ERTISS epithelium (p) & $3(3)$ & $2(2)$ & 0.034 \\
\hline ERTISS stroma (p) & $2(2)$ & $2(3)$ & NS \\
\hline PRTISS epithelium (p) & $6(4)$ & $4(4)$ & 0.0115 \\
\hline PRTISS stroma (p) & $6(4)$ & $5(3)$ & NS \\
\hline
\end{tabular}

*Calculated according to Wilcoxon.

c, cytosol; n, nuclear fraction; TISS, total immune staining score; $\mathrm{p}$, scoring points (a combination of staining intensity and frequency).

trations and the semiquantitative ERTISS and PRTISS obtained in endometriotic tissue and in endometrium are shown in table 1.

EIA showed significant correlation between cycle phase and ERc (oestrogen receptors in cytosol) and ERn (oestrogen receptors in the nuclear fraction) in both endometrium ( $p=0.048$ and $p=0.017$, respectively) and endometriotic tissue $(\mathrm{p}=0.0246$ and $\mathrm{p}=0.039$, respectively). No significant correlation to cycle phase was found for PRc or PRn.

The immunohistochemical evaluation of steroid receptor occurrence showed a significant correlation between cycle phase and ERTISS, both in endometrial epithelium and stroma $(p=0.0181$ and $p=0.0054$, respectively), and PRTISS in endometrial epithelium $(p=0.0157)$. In endometriotic tissue ERTISS in stroma was significantly correlated to cycle phase $(p=0.0356)$. There was a significant correlation between cycle phase and the frequency of ER positive cells in endometrial epithelium ( $p=0.0265)$, stroma $(p=0.0065)$, and the frequency of $P R$ positive cells in endometrial epithelium ( $p=0.0157)$. In endometriotic tissue there was a significant correlation between cycle phase and the frequency of ER positive cells in stroma only ( $p=0.0364)$. The differences found were significant only in the proliferative phase.

The concentration of ERn and PRn was significantly lower in endometriotic tissue than in endometrium (table 1). ERTISS and PRTISS in glandular epithelium were also significantly lower in endometriotic tissue than in endometrium $(p=0.034$ and $p=0.0115$, respectively), but there was no significant difference for the stroma.

In endometrium there was a significant correlation between PRc and PRTISS in epithelium $(p=0.028)$. The correlation was significant between the frequency of $P R$ positive epithelial cells and both PRc $(p=0.0313)$ and PRn $(p=0.042)$ in the proliferative phase. Staining intensity did not correlate significantly with PR concentration. The correlation between ERTISS and ERc or ERn did not reach statistical significance, but the correlation between the frequency of ER positive cells in secretory epithelium and PRTISS in epithelial cells was significant $(p=0.0299)$.

In endometriotic tissue no correlation was found between concentrations of ER or PR and
TISS in either compartment except between ERTISS in epithelial cells and frequency of PR positive cells $(p=0.0193$ ).

The only correlation between tissue types found using the quantitative assays was for ERn $(p=0.0505)$, and the only correlations found when immunocytochemical results were compared was for ERTISS in epithelium $(p=0.0061)$ and stroma $(p=0.0013)$, and PRTISS in epithelium $(p=0.0358)$. Significant correlations were found between the frequency of ER positive cells in endometriotic stroma and ERTISS in endometrial epithelium in the proliferative phase $(p=0.0374)$; between the frequency of PR positive cells in endometrial epithelium and the frequency of ER positive cells in endometriotic epithelium ( $p=0.0364)$; between the frequency of PR positive cells in endometrial stroma and the frequency of ER positive cells in endometriotic stroma ( $p=0.0167)$; and between PRTISS and frequency of ER positive cells in endometrial epithelium in the secretory phase $(p=0.0299)$. No other significant correlations were found between the quantitative immunoassays and the semiquantitative immunocytochemical assays, either in endometrium or in endometriotic tissue.

\section{Discussion}

This study showed that the two techniques used were significantly correlated in endometrium, a tissue consisting nearly exclusively of epithelial and stromal cells. The correlation was most obvious for PR, where EIA particularly correlated to the frequency of positive epithelial cells. A similar correlation was not found for ER. The difference in correlation between PR and ER might depend on the different receptor concentrations. There was a wide range of receptor concentrations, especially in endometrium, corresponding to the pronounced changes between different cycle phases. When EIA was used, the concentration of PR was found to be greater than the concentration of ER in endometrium. In addition, the staining intensity of PR, evaluated by immunocytochemistry, was more pronounced than that for ER, at least in the stromal cells. Thus the strongly PR stained tissue sections might be easier to evaluate visually than the weaker stained ER sections. Thus visual measurement of binding sites might be easier and more appropriate when there is a high staining intensity. These results indicate that when the receptor concentration is high, the addition of non-relevant cells is of minor importance for a quantitative steroid receptor assay in small samples.

No correlation between the techniques was found for endometriotic tissue. This lack of correlation might result from the different composition of the endometriotic tissue compared with the endometrium, with a variation in receptor concentrations in different areas, or differences in steroid receptor binding sites in the two tissue types. Most of the endometriotic samples were scraped from the inside of endometriomas, therefore they comprised blood cells, fibrotic tissue, and pure endometri- 
otic tissue. In endometrium the steroid receptor concentrations varied in the uterine cavity, but this variation is usually systematic, the concentrations being higher in the fundal than in the isthmian area, and higher superficially than close to the basement membrane. ${ }^{19}$ The lack of correlation between the two techniques and no correlation between PR concentrations and cycle phase, clearly strengthen previous data indicating a different regulation of $P R$ in endometriotic tissue than in endometrium ${ }^{20}$ and prompt further discussion about hormonal regulation of this pathological form of endometrium.

When the two tissue types were compared, a correlation was found for ER, both quantitatively and immunocytochemically, in epithelial as well as stromal cells. Although the receptor concentrations were lower in endometriotic tissue than in endometrium, the quantitative ER values correlated significantly to cycle phase in both tissue types. Using a histochemical semiquantitative measure of the receptors, ERTISS correlated significantly with cycle phase in endometrial epithelial and stroma cells, as well as in endometriotic stromal cells.

The role of oestrogen as an endometrial cell mitogen has been well recognised but poorly characterised. $^{21}$ Surprisingly, endometriotic epithelial tissue did not show any correlation between ERTISS and cycle phase. This study has verified that although ER concentration in endometriotic tissue is lower than in endometrium, the synthesis is hormonally regulated and creates one of the prerequisites for oestrogen regulation of endometriotic tissue. Probably factors other than oestrogen are involved in the regulation of steroid receptors in epithelial cells. Some studies have indicated that epithelial growth factor (EGF) is involved in the steroid binding in endometrium. ${ }^{22}$ Immunocytochemical evaluation of EGF in endometriotic tissue has shown lower expression than in endometrium. ${ }^{23}$ Whether epithelial cells are more dependent than stromal cells on EGF is not known. These results do not give any information about the hormonal regulation per se but clearly show that endometriotic tissue (to a much higher degree than endometrium) is a very heterogeneous tissue, in which some parts might be quite well regulated by hormones but others not. Heterogeneous tissue composition is also seen in other pathological structures such as malignancies. Different parts of a tissue may be regulated differently by hormones and other growth regulating factors. However, there is more diffuse bleeding in endometriotic tissue throughout the menstrual cycle compared with endometrium. Minor endometriotic lesions, in the ovaries and other sites, always include fibrotic tissue. Therefore, steroid receptor assays of small tissue samples may not be useful for clinical problem solving.

Usually endometriotic lesions are very small, often not big enough for quantitative steroid receptor assays. This study is unique in that a large number of endometriotic samples, big enough to allow both assays, have been collected. Histological examination of tissue samples revealed different proportions of endometriotic stroma and glandular tissue occurring at random, but no correlation could be found between the proportions of these tissue compartments and the steroid receptor concentrations as the samples were homogenised.

Histological studies have shown that endometriotic, as well as endometrial, epithelium seems to be dependent on stroma cells for survival. ${ }^{24}$ When the stroma cells are replaced with fibrotic tissue during the healing process, the related epithelium will undergo atrophy and often shed. This might be a factor contributing to the common finding of small, isolated atrophic glands without surrounding stroma in ectopic sites. The signalling between epithelial and stromal cells in relation to hormonal influence needs further study.

Green and Press ${ }^{25}$ found that steroid receptors, assayed both in cytosol and nuclear fractions, normally reside in the nuclear compartment both in the presence and absence of steroid. The unoccupied ER assayed in the cytosol fraction of a tissue homogenate are receptors that are loosely associated with nuclear compartments and binding of oestrogen to the receptor leads to a tighter association. When immunocytochemistry is used, the distribution of steroid receptors in the cells is not disturbed. Significant correlations between the two techniques were found only in endometrium, not in endometriotic tissue, but the correlation was significant only for the frequency of positive cells not for staining intensity. Both EIA and immunocytochemistry are valuable techniques for evaluation of steroid receptor status, but the choice of technique is important to obtain the most relevant information about ER and PR concentrations. The two methods are not directly comparable, but complementary, as they use the same type of monoclonal antibodies. Thus a quantitative assay is important to obtain information about the total steroid binding capacity of the tissue. An immunocytochemical technique is valuable to reveal the hormonal sensitivity or the tissue fraction having the ability to respond to steroid hormones. A combination of both techniques would be attractive but is usually not possible in routine clinical practice. Thus ER and PR assays will not be suitable for clinical guidance to hormonal treatment, at least not of endometriosis.

In conclusion, this study shows a high degree of agreement between enzyme immunoassay and immunocytochemistry in measuring steroid receptor concentration in normal homogenous endometrium, but a low degree of agreement in heterogeneous endometriotic tissue. The results suggest that the use of only one of the techniques is not reliable for ER and PR assays in heterogeneous tissues such as endometriotic tissue.

Gunilla Sellberg and Ulla Johansson performed the EIA with great skill. Jorge Tapia is acknowledged for help collecting data. This work was supported by grants B 93-17X-09511-02B from
the Swedish Medical Research Council, Swedish Cancer Foundation, and the Karolinska Institute, Stockholm, Sweden. 
1 King WJ, De Sombre ER, Jensen EV, Greene GL. Comparison of immunocytochemical and steroid-binding assays for estrogen receptor in human breast tumors. Cancer Res 1985;45:293-304.

2 Press MF, Holt JA, Herbst AL, Greene GL. Immunocytochemical identification of estrogen receptor in ovarian carchemical identification of estrogen receptor in ovarian carcinomas. Localisation with monoclonal estrophilin anti-
bodies compared with biochemical assays. Lab Invest 1985; 53:349-61.

3 McCarthy KS Jr, Szabo E, Flowers JL, Cox EB, Leight GS, Miller L, et al. Use of a monoclonal anti-estrogen receptor antibody in the immunohistochemical evaluation of human tumors. Cancer Res 1986;46(suppl):4244S-8S.

4 Pousette Å, Gustafsson SA, Thörnblad AM, Nordgren A, Sällström J, Lindgren A, et al. Quantitation of estrogen receptors in seventy five specimens of breast cancer comparison between an immunoassay (Abbott ER-EIA monoclonal) and a $3 \mathrm{H}$ estradiol binding assay based on isoelectric focusing in polyacrylamide gel. Cancer Res 1986; 46(suppl): $4308 \mathrm{~S}-9 \mathrm{~S}$.

5 Remmele W, Hildebrand U, Hienz A, Klein P-J, Vierbuchen $\mathrm{M}$, Behnken LJ, et al. Comparative histological, histoMemical, immunohistochemical and biochemical studies chemical, immunohistochemical and biochemical studies
on oestrogen receptors, lecitin receptors, and Barr bodies on oestrogen receptors, lecitin receptors, and Barr bodies
in human breast cancer. Virchows Arch (Pathol Anat) 1986; in human breast

6 Charpin C, Jacquemier J, Andrac L, Vacheret A, Habib MC, Devictor B, et al. Multiparametric analysis (SAMBA 200) of the progesterone receptor immunocytochemical assay in nonmalignant and malignant breast disorders. Am $\mathcal{f}$ Patho 1988;132:199-211.

7 Bergqvist A, Rannevik G, Thorell JI. Oestrogen and progesterone cytosol receptor concentration in endometriotic tissue and intrauterine endometrium. Acta Obstet Gynecol Scand 1981;101(suppl):53-8.

8 Lyndrup J, Thorpe S, Glenthöj A, Obel E, Sele V. Altered progesterone/oestrogen receptor ratios in endometriosis. A progesterone/oestrogen receptor ratios in endometriosis. A comparative study of steroid receptors and morphology in endometriosis and

9 Bergqvist A, Fernö M. Oestrogen and progesterone receptors in endometriotic tissue and endometrium: comparison of different cycle phases and ages. Hum Reprod 1993;8:2211-17.

10 Bergqvist A, Fernö M. Estrogen and progesterone receptors in endometriotic tissue and endometrium: comparison according to localisation and recurrence. Fertil Steril 1993 60:63-7.

11 Bur ME, Greene GL, Press MF. Estrogen receptor localisation in formalin-fixed, paraffin-embedded endometrium and endometriotic tissue. Int f Gynecol Pathol 1987;6:14051 .
12 Lessey BA, Metzger DA, Haney AF, McCarty KS Jr. Immuno-histochemical analysis of estrogen and progesterone receptors in endometriosis: comparison with normal endometrium during the menstrual cycle and the effect of medical therapy. Fertil Steril 1989;51:409-15.

13 Bergqvist A, Ljungberg O, Skoog L. Immunohistochemical analysis of oestrogen and progesterone receptors in endometriotic tissue and endometrium. Hum Reprod 1993; 8:1915-22.

14 Schweppe K-W, Wynn RM. Ultrastructural changes in endometriotic implants during the menstrual cycle. Obstet Gynecol 1981;58:465-73.

15 Bergqvist A, Ljungberg O, Myhre E. Human endometrium and endometriotic tissue obtained simultaneously: a comparative histological study. Int $\mathcal{F}$ Gynecol Pathol 1984;3: 135-45.

16 Thorpe SM, Lykkesfeldt AE, Vinterby A, Lonsdorfer M. Quantitative immunological detection of estrogen receptors in nuclear pellets from human breast cancer biopsies. Cancer Res 1986;46:4251-5.

17 Burton K. A study of conditions and mechanisms of the diphenylamine action for the colorimetric estimation of deoxyribonucleic acid. Biochem $\mathcal{F}$ 1956;62:315-23.

18 Noyes RW, Hertig AT, Rock J. Dating the endometrial biopsy. Fertil Steril 1950;1:3-25.

19 Tsibris JCM, Fort FL, Casenave CR, Cantor B, Bardawil WA, Notelowitz $M$, et al. The uneven distribution of estrogen and progesterone receptors in human endometrium. $f$ Steroid Biochem 1981;14:997-1003.

20 Bergqvist A. Hormonal regulation of endometriosis and the rationales and effects of gonadotrophin-releasing hormone agonist treatment: a review. Hum Reprod 1995;10:446-52.

21 Olive DL, Montoya I, Riehl RM, Schenken RS. Macrophage-conditioned media enhance endometrial stromal cell proliferation in vitro. Am $\mathcal{f}$ Obstet Gynecol 1991;164:953-8.

22 Haining REB, Cameron IT, van Papendorp C, Davenport AP, Prentice A, Thomas EJ, et al. Epidermal growth factor in human endometrium: proliferative effects in culture and immunocytochemical localisation in normal and endometriotic tissues. Human Reprod 1991;6:1200-5.

23 Bergqvist A, Borg Å, Ljungberg O. Protooncogenes in endometriotic and endometrial tissue. Ann NY Acad Sci 1991;626:276-83.

24 Roberts DK, Walker NJ, Lavia LA. Ultrastructural evidence of stromal/epithelial interactions in the human endometrial cycle. Am F Obstet Gynecol 1988;158:854-61.

25 Greene GL, Press MF. Structure and dynamics of the oestrogen receptor. $\mathcal{F}$ Steroid Biochem 1986;24:1-7. 